\title{
Poluição atmosférica: estudo de caso do Município de São Luís do Maranhão
}

\section{Atmospheric pollution: a case study of the Municipality of São Luís do Maranhão}

\author{
Juarez Mota Pinheiro 1 \\ Luis Antônio Bittar Venturi ${ }^{2}$ \\ Emerson Galvani ${ }^{3}$
}

Palavras-chave:

Partículas Totais em Suspensão

Partículas Inaláveis

Fatores Geográficos

\begin{abstract}
Resumo:
As capitais brasileiras têm apresentado problemas ambientais atmosféricos de diversas ordens, repercutindo negativamente na qualidade de vida de seus habitantes. São Luís, capital do estado do Maranhão, com uma população de mais de 1 milhão de habitantes constitui um bom exemplo de capital brasileira que também convive com problemas ambientais atmosféricos. A pesquisa ao analisar a poluição atmosférica da cidade de São Luís procurou também correlacionar com seus aspectos geográficos (físicos e humanos) por entender que somente é possível compreender a complexidade do problema não se limitando apenas às suas fontes poluidoras e volumes emitidos. Os dados coletados foram obtidos de sete estações automáticas de monitoramento de qualidade do ar pertencentes à Companhia Vale S/A dentro do município de São Luís e orientados para uma análise evolutiva e integrada. Os resultados alcançados pela pesquisa indicaram que a estação EMAP, localizada na zona portuária do município, foi a única que apresentou valores que ultrapassaram os limites estabelecidos pela Lei com os seguintes valores de porcentagens para Particulados Inaláveis nos seguintes anos: em 2013 (68\%); 2014 (87\%); 2015 (110\%) e 2016 (2\%). Também foi possível identificar que entre os meses de julho a dezembro, na estação seca, foram identificados aumentos significativos dos índices de poluição atmosférica na ordem de 25,6\% para Particulados Inaláveis e 35\% para Particulados Totais em Suspensão. Concluímos que além das fontes poluidoras, no caso de São Luís, a pluviosidade e o vento são fatores geográficos preponderantes na determinação dos níveis de poluição na cidade.
\end{abstract}

Keywords:

Total Suspended Particles

Inhalable Particles

Geographical Factors

\begin{abstract}
:
The Brazilian capitals have been presenting environmental problems of diverse orders, reverberating negatively in the life quality of its inhabitants. São Luís, the State of Maranhão's capital, with a population of larger than 1 million citizens consists of a good example of a Brazilian capital that can coexist with environmental atmospheric problems. The research when analyzing the atmospheric pollution in the city further sought to correlate with its geographic aspects (physical and human) by comprehending that it's only possible to discern the complexity of the problem when it's not
\end{abstract}

\footnotetext{
${ }^{1}$ Prof. Dr. Departamento de Geociências - UFMA - São Luís, MA, Brasil. juarez.mp@ufma.br

${ }^{2}$ Prof. Dr. Departamento de Geografia - USP - São Paulo, SP, Brasil. luisgeo@usp.br

${ }^{3}$ Prof. Dr. Departamento de Geografia - USP - São Paulo, SP, Brasil. egalvani@usp.br
} 
limited only to the pollution sources and the emitted volumes. The collected data were obtained from seven automatic stations of air quality belonging to Company Vale S/A and oriented by an evolutive and integrated analysis. The achieved results by the study indicated that the EMAP station, localized in the county's port zone, was the sole one that presented values that exceeded the established limits by the Law with the subsequent values in percentages for Unbreathable Particles in the following years: in 2013 (68\%); 2014 $(87 \%) ; 2015(110 \%)$ and $2016(2 \%)$. It was also possible to distinguish between the months from July to December, in the dry season, significant rises in the atmospheric pollution indexes in the order of $24,5 \%$ for Unbreathable Particles and $35 \%$ for Total Particles in Suspension. It is concluded beyond polluting sources, that in São Luís case, the rainfall and wind are climatic atributes significant in the determination the levels of pollution in the study area.

\section{INTRODUÇÃO}

A poluição atmosférica que se caracteriza pela emissão de gases tóxicos e de materiais particulados na atmosfera, seja de fontes de poluição natural (poeira produzida pelo vento, gás metano da decomposição biológica da matéria orgânica, erupções vulcânicas e etc) ou antrópica, advinda em grande parte das grandes aglomerações urbanas e industriais, gerada principalmente pela grande presença de automóveis e da emissão gases tóxicos no processo industrial, são os responsáveis por colocar em risco a qualidade de vida de muitos dos seres vivos no planeta.

A poluição atmosférica nas cidades tem como principal efeito negativo afetar a saúde humana. Lopes (2004) destaca que entre os diversos efeitos do ar poluído na saúde humana, o principal sistema orgânico acometido é o respiratório, devido à deposição de partículas no interior do organismo. Além de provocar doenças das vias respiratórias, também são identificadas doenças cardiovasculares, dermatológicas, gastrointestinais, problemas oftálmicos e tipos de câncer que se originam a partir da presença de poluição atmosférica no ambiente (PEITER; TOBAR, 1998). Gouveia et al. (2006), analisando a associação entre poluição atmosférica por Material Particulado (MP) e as internações hospitalares no Município de São Paulo, constataram que um aumento de $10 \mu \mathrm{g} \mathrm{m}^{-3}$ de Partículas Inaláveis (PI) está associado ao incremento de 4,6\% nas internações por asma em crianças, de $4,3 \%$ por doença pulmonar obstrutiva crônica e de $1,5 \%$ por doença isquêmica do coração em idosos.

Alguns pesquisadores, dentre eles Peiter e Tobar (1998), afirmam que, nas cidades industriais, a emissão de gases tóxicos e particulados pelas indústrias somadas à poluição provocada pela circulação de veículos, geram muitas vezes situações muito críticas para a saúde da população. A poluição atmosférica é, sem dúvida, um fator de risco muito sério para a saúde humana. Destaca-se também um fato grave ocorrido em 1952, onde cerca de 4 mil pessoas morreram na região de Londres devido intoxicação por $\mathrm{SO}_{2}$ proveniente da queima de carvão. Um súbito resfriamento na atmosfera causado por inversão térmica aprisionou os poluentes sobre a população.

A resolução do Conselho Nacional do Meio Ambiente (CONAMA) n03/90, que regulamenta as condições atmosféricas brasileiras, conceitua poluição atmosférica da seguinte forma em seu Art. $1^{\circ}$ - Parágrafo único:

Entende-se como poluente atmosférico qualquer forma de matéria ou energia com intensidade e quantidade, concentração, tempo ou características em desacordo com os níveis estabelecidos, e que tornem ou possa tornar o ar: impróprio, nocivo ou ofensivo à saúde; inconveniente ao bemestar público; danoso aos materiais, à fauna e flora; prejudicial à segurança, ao uso e gozo da propriedade e as atividades normais da comunidade (BRASIL, 1990, p.342).

Para a OMS (Organização Mundial da Saúde) a poluição atmosférica é conceituada como "contaminação dos ambientes internos ou externos por qualquer composto químico, físico ou agente biológico que modifique as características naturais da atmosfera". A emissão de gases poluentes altera a composição química da atmosfera, o que leva a modificações do equilíbrio ambiental, com impactos diretos na saúde da população. 
Afirma ainda o Ministério do Meio Ambiente - (MMA, 2009) que os efeitos à saúde da população por material particulado indicam ocorrências de: câncer respiratório, arteriosclerose, inflamação de pulmão, agravamento de sintomas de asma, aumento de internações hospitalares que podem levar à morte.

A poluição atmosférica pode ocorrer de diversas formas e ser gerada por diversos vetores. Da Silva (2016) constatou em pesquisa que a ocorrência de queimadas, veículos desregulados, padrões construtivos urbanos inadequados e ruas sem cobertura asfáltica podem contribuir muito mais significativamente para a geração de poluição do ar do que contaminantes provenientes das indústrias.

Destaca-se também que, além dos efeitos na saúde da população provocados pela poluição atmosférica, outro condicionante significativo e determinante para a compreensão do problema da poluição atmosférica nas cidades, são os fatores geográficos presentes e atuantes no ambiente urbano que são fundamentais para o entendimento de como promovem as condições de intensificação e resiliência das especificidades poluidoras. Muitos autores, como Miller (2007); Braga et al. (2005); Davis e Cornwell (2008), apontam que nos espaços urbanos o nível da qualidade do ar, em certa medida, é condicionado pelas características socioambientais. Zheng et al (2017) estudando a relação da poluição atmosférica com os padrões de uso da terra constatou que a ocorrência é maior dos valores de poluição nos espaços de intenso uso da terra em comparação a espaços mais vegetativos, como também de variação maior de poluição no período de inverno. Estes estudiosos destacam que as características atmosféricas como do vento, em sua direção e intensidade, da temperatura, da pluviosidade, da umidade do ar, bem como da geomorfologia e as atividades econômicas condicionam a espacialidade e intensidade da poluição.

A geografia física de uma localidade pode determinar a qualidade do ar de uma cidade cujas emissões atmosféricas cotidianas são agravadas pelas características de sua geomorfologia e clima, dificultando ainda mais as condições de dispersão dos poluentes, pode-se citar a cidade de Santiago no Chile que segundo Garreaud e Rutllant (2006), determina que na cidade, no período do inverno, torne-se muito mais suscetível a episódios de ocorrências intensas de inversão térmica. Outro pesquisador
Tian et al (2018) ao estudar os efeitos da poluição na população de Hangzhou, na China identificou que os níveis de poluição varia conforme as estações do ano e seus impactos são mais graves no inverno e menores no verão.

Deste modo, os objetivos da pesquisa foram de constatar os níveis de poluição atmosférica no município de São Luís onde permitissem avaliar tanto o ambiente urbano, quanto rural e industrial em correlação com seus aspectos geográficos, principalmente o vento e a chuva. Estudos que buscam monitorar a qualidade do ar por poluentes, em que se procura quantificálos e espacializá-los visa, sobretudo, garantir a saúde da população e de todos os seres vivos, além de fomentar um desenvolvimento socioeconômico sustentável e ambientalmente seguro com possibilidades de prevenção, combate e redução das emissões dos poluentes.

Neste sentido a pesquisa procura requalificar a importância de se ter uma visão integrada do problema poluição atmosférica, não se limitando apenas as fontes geradoras, incluindo também na análise a interferência dos fatores geográficos, como também, a pesquisa preenche uma lacuna de investigação sobre o tema poluição atmosférica envolvendo cidades de baixa latitude numa zona de transição morfoclimática entre a Amazônia de clima quente e úmido e o Nordeste de clima semiárido com características geográficas muito particulares.

\section{Localização e caracterização geográfica da área de estudo}

O Município de São Luís localiza-se no nordeste brasileiro e a norte do estado do Maranhão, encontra-se situada na região litorânea do estado, em uma ilha costeira dentro do Golfão Maranhense (Figura 1). Sua topografia se apresenta aplainada e é caracterizada por um relevo plano por todo o município de São Luís, refletindo que sua altitude cujo ponto mais elevado alcança 70 metros (SILVA, 2012), sofre também influência direta da maritimidade e por estar localizada geograficamente em baixa latitude - especificamente a $2^{\circ} 30^{\prime} \mathrm{S}$, proporciona uma configuração climática que, associada às condições de atuação regional das massas de ar quente e dos mecanismos atmosféricos tropicais, produz a existência de médias térmicas de baixa variabilidade tanto nas variações diárias, quanto nas variações ao longo de todo o ano, porém de elevada temperatura. 
Figura 1: Mapa de localização do município de São Luís

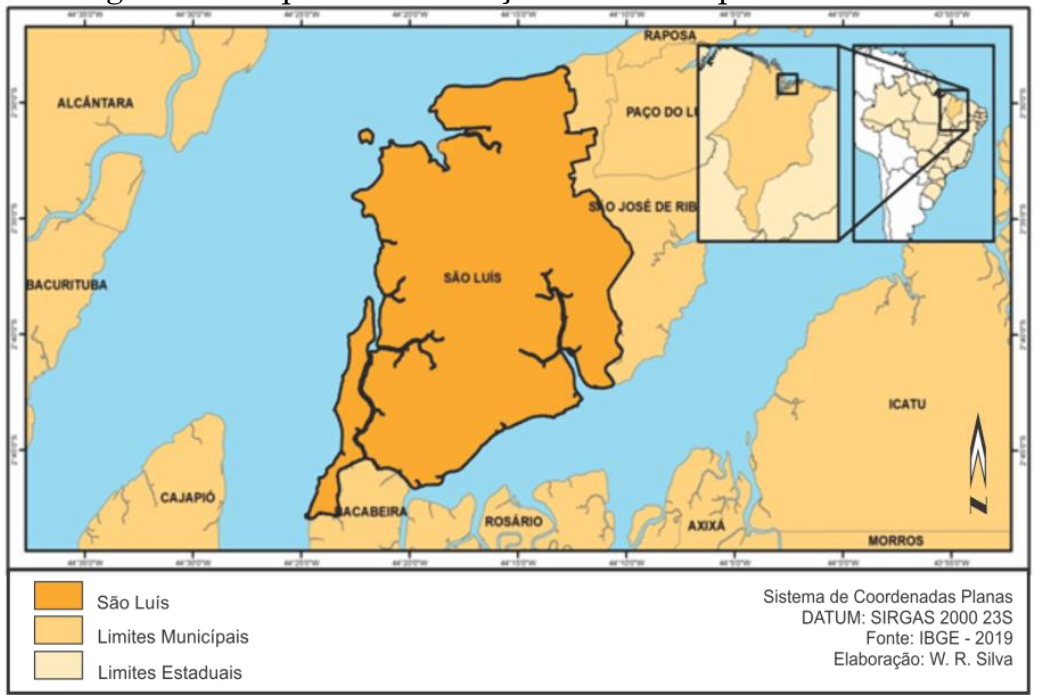

Fonte: IBGE (2019).

A perpendicularidade dos raios solares atuantes na superfície do município, faz predominar a pouca variabilidade térmica e a ausência dos ciclos sazonais das estações climáticas de primavera, verão, outono e inverno, estabelecendo, como afirma Pinheiro (2018), uma classificação da existência de apenas duas estações, uma estação chuvosa (janeiro a junho) e uma estação seca ou de estiagem (julho a dezembro). Ao se observar a Normal Climatológica do INMET da pluviosidade e temperatura para São Luís é possível identificar essas características, (Figura 2).

Figura 2: Gráfico da Normal Climatológica (1981-2010) de pluviosidade e temperatura para São Luís $-\mathrm{MA}$

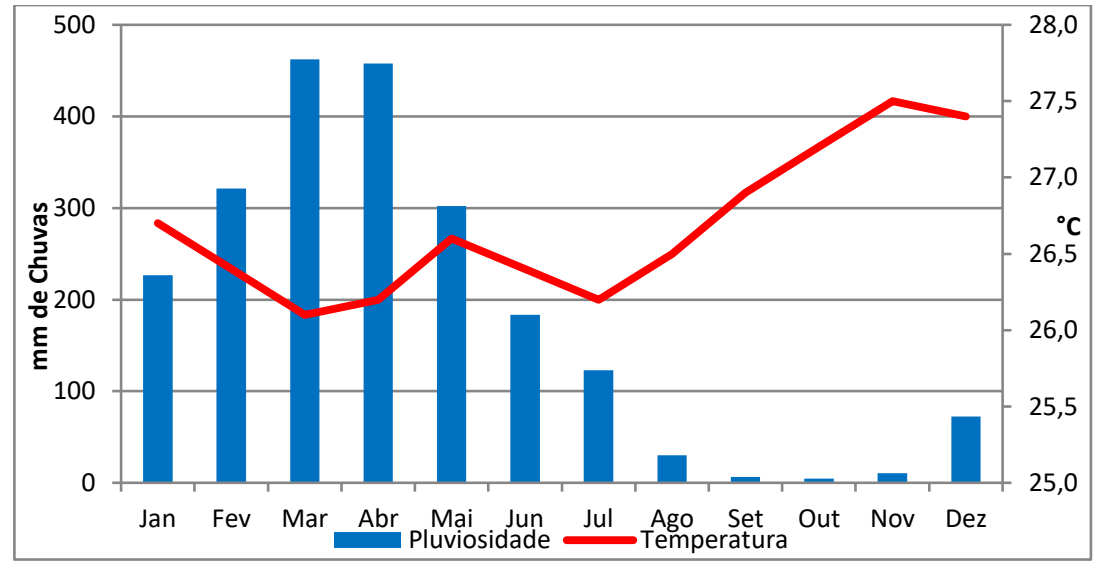

Fonte de dados: INMET. Org.: Autores, 2019.

Ainda segundo Pinheiro (2018) Os principais sistemas atmosféricos presentes e atuantes no município de São Luís são, em destaque, a Zona de Convergência Intertropical (ZCIT) responsável pela determinação anual do período chuvoso e de estiagem, e a influência dos Ventos Alísios responsáveis pela atuação dos ventos constantes de origem regional e carregados de umidade. Em nível secundário de atuação, os Vórtices Ciclônicos de Altos Níveis (VCANs), gerando períodos de estabilidade atmosférica com estiagem; a Alta Subtropical do Atlântico Sul (ASAS), os Distúrbios Ondulatórios de Leste (DOL) e as Linhas de Instabilidade (LI) com a geração de períodos curtos de chuvas na região e, em uma escala local de influência, a brisa marítima com ventos diários e chuvas ocasionais por sistemas convectivos.

Outra variável importante de sua configuração climática e que possui influência direta para compreensão das condições de poluição atmosférica do município estão relacionadas ao vento, Figura 3. 
Figura 3: Gráfico da Rosa dos Ventos da Normal Climatológica (1981-2010) da direção e intensidade dos ventos em São Luís.

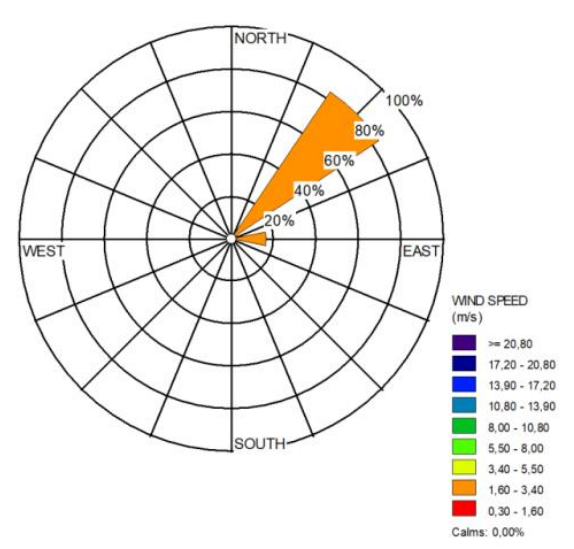

Fonte de dados: INMET. Org.: Autores, 2020.

Destaca-se de acordo com a Figura $3 \mathrm{da}$ Normal Climatológica de São Luís, que $82 \%$ dos ventos são predominantemente de direção Nordeste e $18 \%$ de direção Leste e sua intensidade média varia entre $1,6 \mathrm{~m} / \mathrm{s}$ a 3,40 $\mathrm{m} / \mathrm{s}$. Segundo Pinheiro e Galvani (2018) as maiores intensidades do vento, em São Luís, são registradas nos meses de setembro a dezembro e o quadrimestre de menor intensidade dos ventos são os meses de março a junho. Seus ventos se caracterizam por serem constantes e de pouquíssima ocorrência de calmaria, porém, de baixa intensidade considerada segundo a Escala Beaufort, brisas fracas.

\section{MATERIAIS E MÉTODOS}

Optou-se por dois parâmetros de materiais particulados geradores de poluição atmosférica para a pesquisa: Partículas Totais em Suspensão (PTS) e Partículas Inaláveis (PI). A escolha desses dois particulados decorreu pelo fato desses elementos apresentarem dados em quantidade consistentes dos anos estudados, como também representarem valores de poluição que identificam tanto a poluição proveniente da queima de combustíveis fósseis (veículos automotores, biomassa vegetal), quanto de material em suspensão proveniente da ação do vento.

Segundo o MMA (2009), Material Particulado é constituído por:

Uma mistura complexa de sólidos com diâmetro reduzido, cujos componentes apresentam características físicas e químicas diversas. Em geral o material particulado é classificado de acordo com o diâmetro das partículas, devido à relação existente entre diâmetro e possibilidade de penetração no trato respiratório.

No Brasil, os padrões de qualidade do ar foram estabelecidos pela Resolução CONAMA n ${ }^{\circ}$ 3 de 28 de junho de 1990, que complementa a Resolução CONAMA n ${ }^{\circ} 5$, de 15 de junho de 1989, na qual instituiu o Programa Nacional de Controle da Qualidade do Ar - PRONAR. Com esta Resolução foram determinados os padrões nacionais de qualidade do ar para os poluentes atmosféricos: a) Partículas Totais em Suspensão - PTS e b) Partículas Inaláveis - PI, utilizados na pesquisa. A Resolução 3/90 CONAMA, ao estabelecer os padrões de monitoramento para valores médios diários e anuais para os poluentes PTS e PI, também determinou que os índices diários não devem exceder em mais de uma vez por ano os seus valores, Tabela 1. 
Tabela 1 - Valores de concentração média dos padrões de qualidade do ar para Partículas Totais em Suspensão (PTS) e Partículas Inaláveis (PI) determinados pela Resolução nº 3/90 - CONAMA.

\begin{tabular}{c|c|c}
\hline \multirow{2}{*}{ Poluentes } & \multicolumn{2}{|c}{ Padrão Primário } \\
\cline { 2 - 3 } & CONAMA $($ concentração máxima $)$ & Referência Temporal \\
\hline Partículas Totais em & $80\left(\mu \mathrm{g} / \mathrm{m}^{3}\right)$ & Um ano \\
\cline { 2 - 3 } Suspensão - PTS & $240\left(\mu \mathrm{g} / \mathrm{m}^{3}\right)$ & 24 horas \\
\hline \multirow{2}{*}{ Partículas Inaláveis - PI } & $50\left(<10 \mu \mathrm{m}^{3}\right)$ & Um ano \\
\cline { 2 - 3 } & $150\left(<10 \mu \mathrm{m}^{3}\right)$ & 24 horas \\
\hline
\end{tabular}

Fonte: Resolução n 3/90 - CONAMA (BRASIL, 1990).

Segundo determina a norma da Resolução para poluição por PTS, a concentração média anual não deve ultrapassar 80 (oitenta) microgramas por metro cúbico de ar, e para concentrações médias de 24 (vinte e quatro) horas não deve ultrapassar 240 (duzentos e quarenta) microgramas por metro cúbico de ar. Para poluidores de PI, a concentração média geométrica anual não deve ultrapassar 50 (cinquenta) microgramas por metro cúbico de ar e para concentrações médias de 24 (vinte e quatro) horas não deve ultrapassar 150 (cento e cinquenta) microgramas por metro cúbico de ar.

A cidade de São Luís possui sete estações automáticas de monitoramento da qualidade do ar, pertencentes à Companhia Vale S/A, administrados através da empresa terceirizada ECOSOFT que as instalou e as gerencia. Todas as estações automáticas de monitoramento do ar estão localizadas geograficamente dentro do município de São Luís (Tabela 2) e os dados adquiridos representam parâmetros diários coletados todos os dias, a cada hora, dos anos de 2013 a 2016 em todas as estações. Destacamos também que alguns dados coletados das séries apresentaram inconsistências ou falhas indicando que em alguns dias ocorreram registros imprecisos, incompletos ou ausentes. Optamos por não aplicar nenhuma técnica estatística de correção das falhas e onde ocorreram as incongruências estes dias foram descartados.

Tabela 2 - Localização das Coordenadas Geográficas das Redes Automáticas de Monitoramento da Qualidade do Ar em São Luís.

\begin{tabular}{c|c|c|c}
\hline \multicolumn{2}{|c|}{ REDES AUTOMÁTICAS DE MONITORAMENTO DA QUALIDADE DO AR - RAMQA } \\
\hline & \multicolumn{1}{|c|}{ ESTAÇÕES } & Latitude S & \multicolumn{2}{c}{ Longitude O } \\
\hline 1 & RAMQA - Estação Calhau & $2^{\circ} 29^{\prime} 40,32^{\prime \prime}$ & $44^{\circ} 16^{\prime} 43,78^{\prime \prime}$ \\
\hline 2 & RAMQA - Estação Centro & $2^{\circ} 32^{\prime} 09,76^{\prime \prime}$ & $44^{\circ} 17^{\prime} 32,25^{\prime \prime}$ \\
\hline 3 & RAMQA - Estação UEMA & $2^{\circ} 34^{\prime} 48,10^{\prime \prime}$ & $44^{\circ} 12^{\prime} 33,50^{\prime \prime}$ \\
\hline 4 & RAMQA - Estação Posto de Saúde Bacanga & $2^{\circ} 33^{\prime} 56,22^{\prime \prime}$ & $44^{\circ} 19^{\prime} 13,98^{\prime \prime}$ \\
\hline 5 & RAMQA - Estação Vila Maranhão & $2^{\circ} 37^{\prime} 29,69^{\prime \prime}$ & $44^{\circ} 18^{\prime} 58,29^{\prime \prime}$ \\
\hline 6 & RAMQA - Estação EMAP & $2^{\circ} 34^{\prime} 34,48^{\prime \prime}$ & $44^{\circ} 21^{\prime} 58,17^{\prime \prime}$ \\
\hline $\mathbf{7}$ & RAMQA - Estação CE Y Bacanga & $2^{\circ} 33^{\prime} 40,72^{\prime \prime}$ & $44^{\circ} 20^{\prime} 09,04^{\prime \prime}$ \\
\hline
\end{tabular}

Fonte: Autores, 2019.

Para uma melhor visualização da localização das Estações Automáticas de Monitoramento da
Qualidade do Ar no município de São Luís, a Figura 4 identifica suas localizações geoespaciais. 
Figura 4 - Localização das Redes Automáticas de Monitoramento da Qualidade do Ar - RAMQA em São Luís - MA.

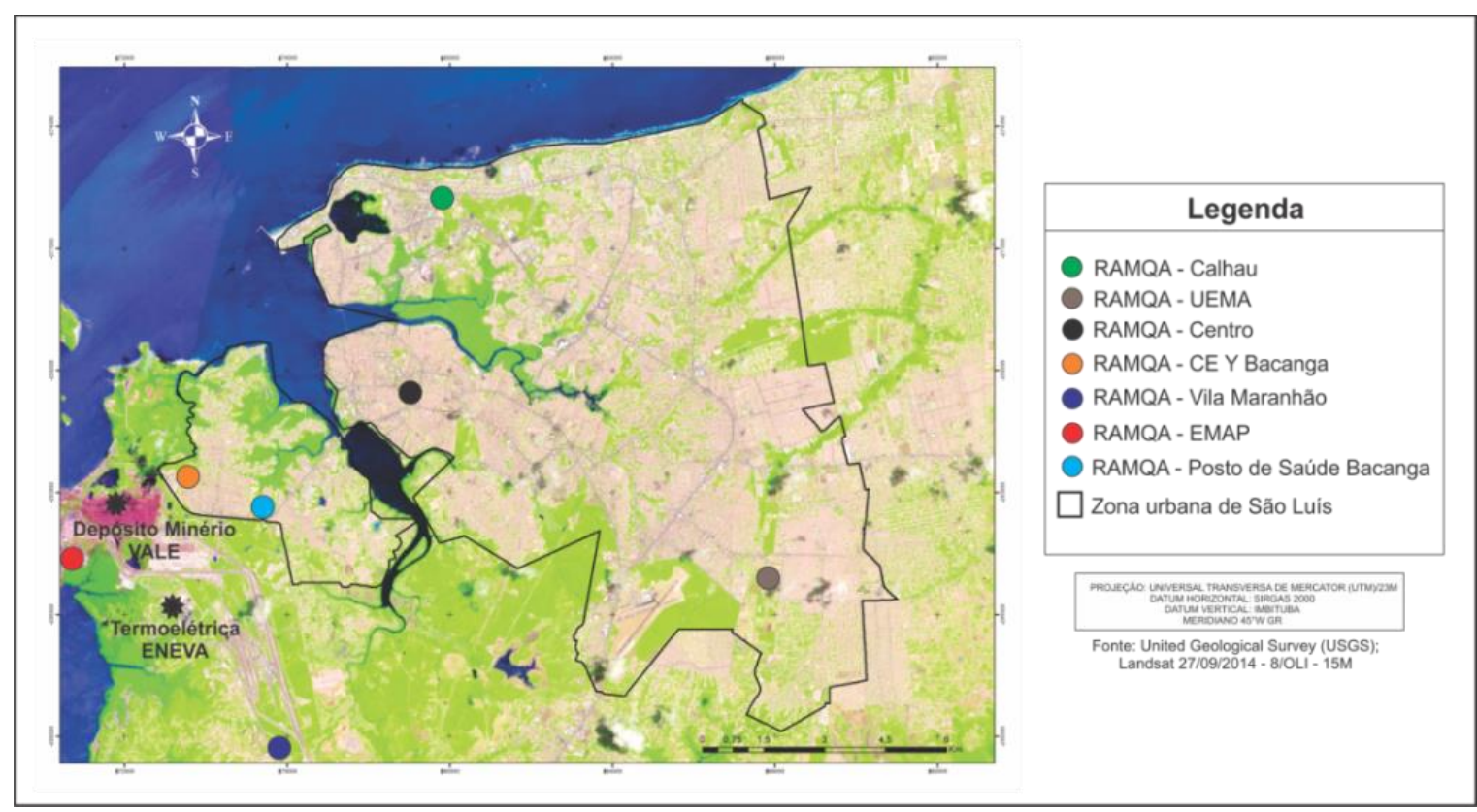

Fonte: United Geological Survey (USGS), Org.: Autores, 2019.

As observações a serem destacadas são, primeiramente, que das sete estações de monitoramento utilizadas na pesquisa, cinco estão localizadas dentro da zona urbana de São Luís (Estação Calhau - Estação UEMA Estação Centro - Estação Posto de Saúde Bacanga - Estação CE Y Bacanga), uma na zona portuária (Estação EMAP) e a última no distrito industrial do município (Estação Vila Maranhão). O outro destaque observado no mapa de localização das estações são as localizações de dois empreendimentos propensos a serem grandes geradores de poluição do ar: o local de deposição e estocagem do minério de ferro proveniente de Carajás-PA pertencente à Companhia VALE S/A, e o outro a Termoelétrica movida a carvão mineral da empresa ENEVA S/A.

\section{RESULTADOS E DISCUSSÃO}

Inicialmente, para os índices de média anual
(Figuras 5 e 6) foram dispostas todas as estações e os anos utilizados na pesquisa. Observamos que ocorreram falhas nos dados coletados por algumas estações para a geração da média anual, não sendo possível a sua representação.

Com o gráfico da figura 5 identificamos que a estação EMAP localizada na zona portuária do município foi a única a ultrapassar os parâmetros estabelecidos pela Resolução 3/90 CONAMA para poluentes por PTS $\left(\mu \mathrm{g} / \mathrm{m}^{3}\right)$ e isto ocorreu no ano de 2016 com valores médios anuais registrados de $80,9 \mu \mathrm{g} / \mathrm{m}^{3}$, um valor que ultrapassou em $0,9 \mu \mathrm{g} / \mathrm{m}^{3}$ os limites estabelecidos pela Resolução. $\mathrm{Na}$ zona portuária, onde se encontra o Porto do Itaqui através do qual são transportados, dentre outros produtos, o minério de ferro proveniente de Carajás-PA, avalia-se que a movimentação de cargas do Porto e, principalmente, de minério de ferro, estaria sendo a responsável pela geração desses índices de poluição do ar. 
Figura 5 - Gráfico da média anual das Estações de Monitoramento da Qualidade do Ar em São Luís para poluição por PTS $\left(\mu \mathrm{g} / \mathrm{m}^{3}\right)$ em comparação com os limites estabelecidos pela Resolução CONAMA $3 / 90$ no período de 2013 a 2016.

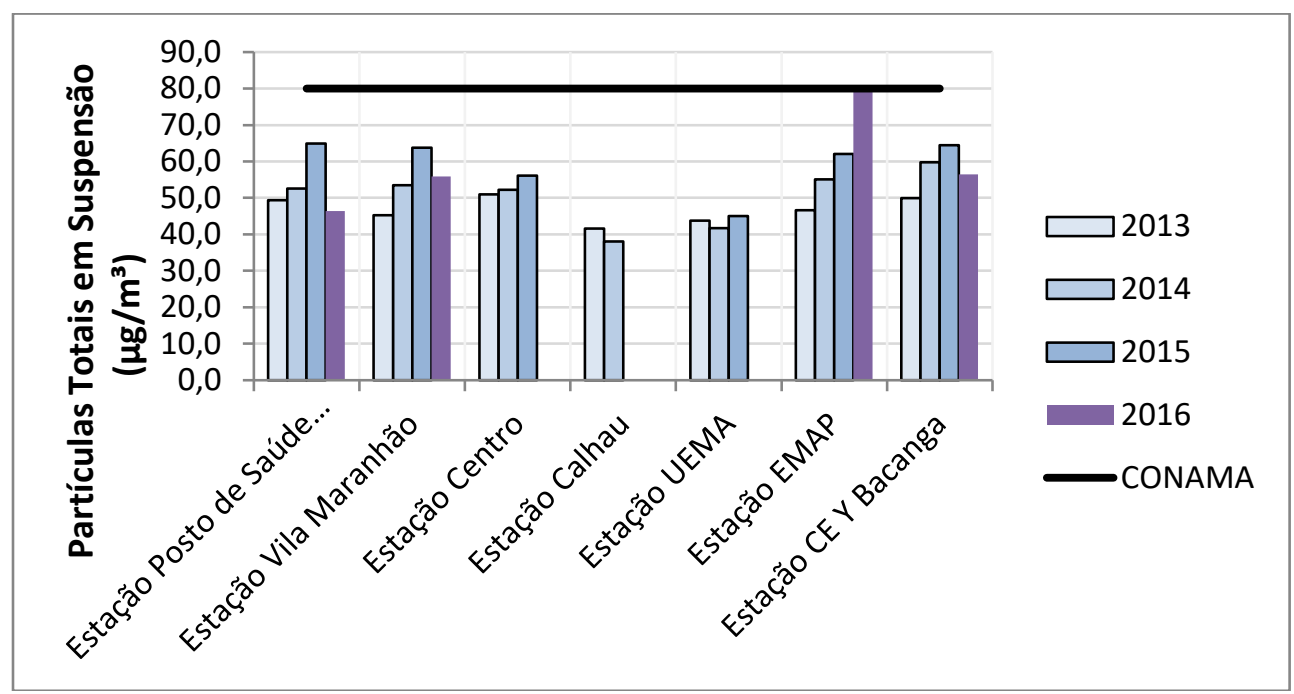

Fonte: VALE/Ecosoft - Org.: Autores, 2019.

A seguir, na figura 6, organizamos, por estação e por ano, os valores de média anual para os parâmetros de poluição de Partículas Inaláveis em índices de $<10 \mu \mathrm{m}^{3}$. Destacamos também, com relação ao gráfico, que não foi possível a representação gráfica de alguns anos, em algumas estações, em função de falhas na coleta dos dados pelos equipamentos.

Figura 6 - Gráfico da média anual das Estações de Monitoramento da Qualidade do Ar em São Luís para poluição por PI $\left(\mu \mathrm{m}^{3}\right)$ em comparação com os limites estabelecidos pela Resolução CONAMA $3 / 90$ no período de 2013 a 2016.

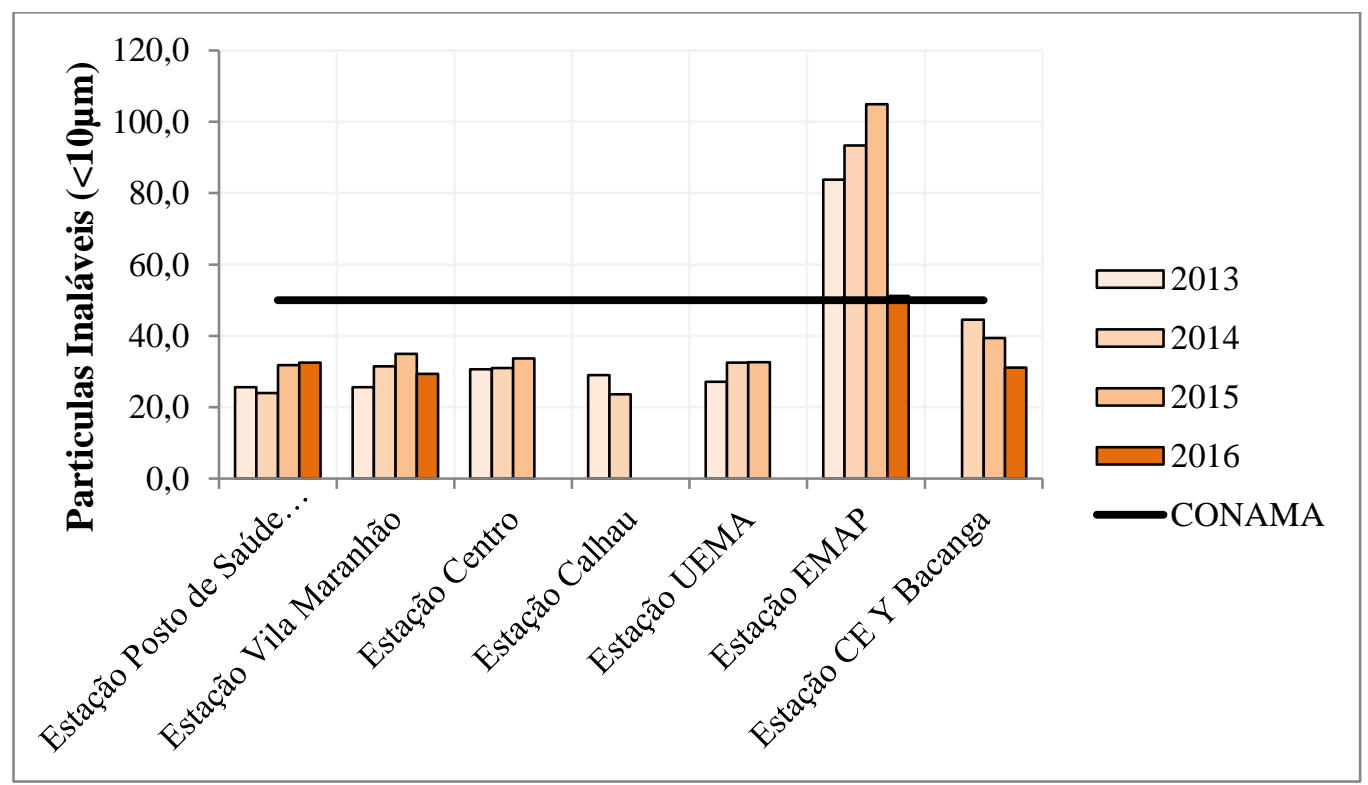

Fonte: VALE/Ecosoft - SEMA - Org.: Autores, 2019. 
O destaque negativo apresentado nos valores de poluição para poluição por $\mathrm{PI}\left(<10 \mu \mathrm{m}^{3}\right)$, para todos os anos registrados, foi a Estação EMAP que excedeu os limites de poluição estabelecidos pela Resolução 3/90 - CONAMA. A estação EMAP ultrapassou os limites de poluição de Partículas Inaláveis em 68\% com valores de 83,8 $\left(<10 \mu \mathrm{m}^{3}\right)$ no ano de 2013 , em $87 \%$ com valores de 93,4 $\left(<10 \mu \mathrm{m}^{3}\right)$ no ano de 2014, em $110 \%$ com valores de $105\left(<10 \mu \mathrm{m}^{3}\right)$ no ano de 2015 e em $2 \%$ com valores de 51,1 $\left(<10 \mu \mathrm{m}^{3}\right)$ no ano de 2016 . Após consulta ao site do Ministério da Economia identificamos que o ano de 2016 foi quando o Brasil atingiu o menor volume de exportação de minério de ferro dos quatro anos estudados.

A identificação desta situação demarca uma grave situação da poluição do ar por PI em todos os anos, em uma área administrada e controlada, em sua grande parte, pela Companhia Vale S/A que, principalmente, através da movimentação de minério de ferro, está gerando graves índices de poluição do ar. A Termoelétrica é outra empresa que, estando dentro da área de influência de registros da Estação EMAP, deve ter também suas atividades mais bem monitoradas. Constatamos também que as outras estações de monitoramento dentro da zona urbana de São Luís apresentaram índices aceitáveis de poluição do ar por PI e PTS, determinando que os volumes de poluição automotiva ainda não estão sendo capazes de ultrapassar os limites estabelecidos pela Resolução.

Para os parâmetros de concentração de poluição por PTS $\left(\mu \mathrm{g} / \mathrm{m}^{3}\right)$ e PI $\left(<10 \mu \mathrm{m}^{3}\right)$, em comparação com os valores limites estabelecidos pela Resolução CONAMA 3/90 nos quatro anos estudados em seus valores diários, produzimos os gráficos que estão representados nas figuras 7 e 8 .

Figura 7 - Gráficos das médias diárias de todas as Estações de Monitoramento da Qualidade do Ar em São Luís para poluição por PTS $\left(\mu \mathrm{g} / \mathrm{m}^{3}\right)$ em comparação com os limites estabelecidos pela

Resolução CONAMA 3/90 nos anos de 2013, 2014, 2015 e 2016.

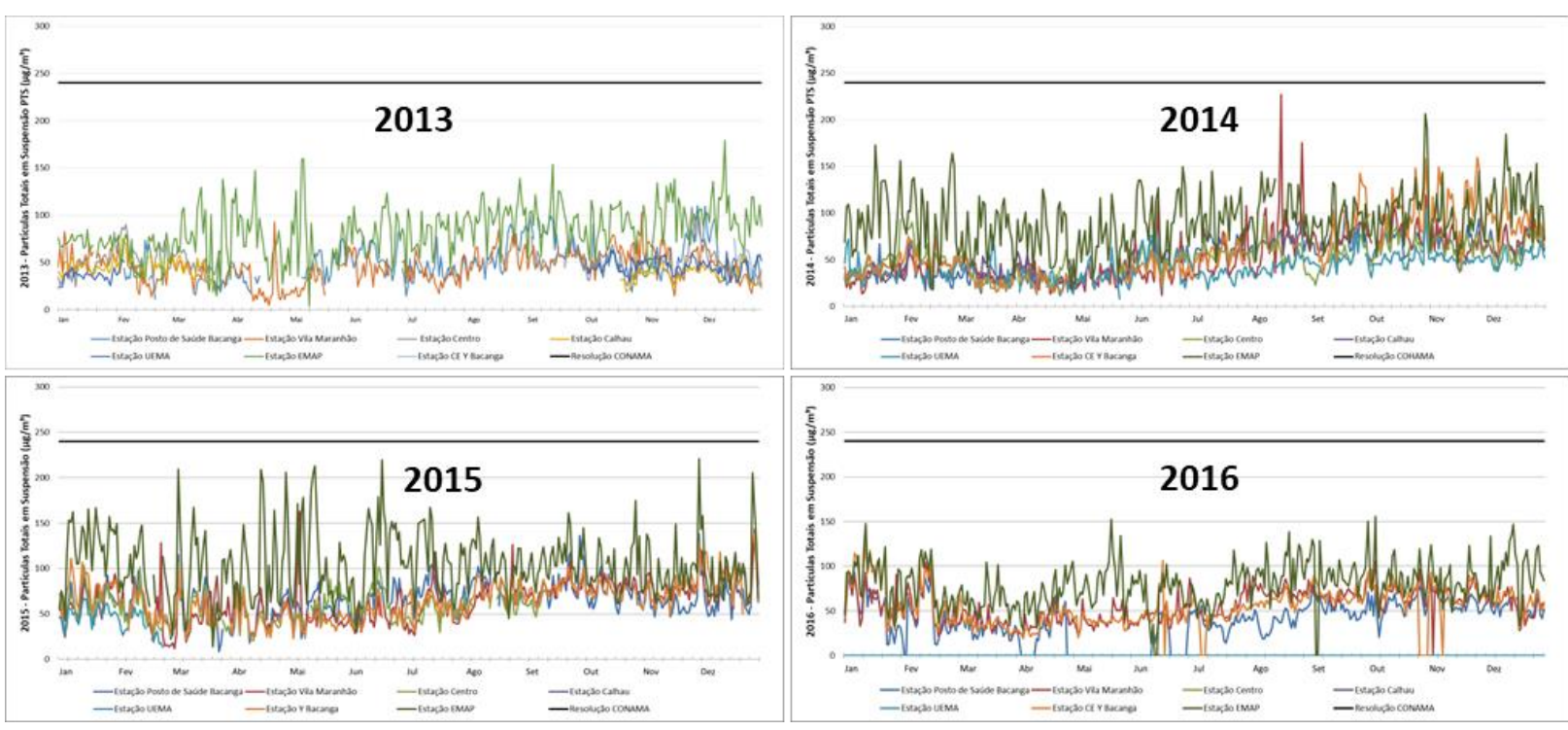

Fonte: VALE/Ecosoft - Org.: Autores, 2019 
Figura 8-Gráficos das médias diárias de todas as Estações de Monitoramento da Qualidade do Ar em São Luís para poluição por PI $\left(<10 \mu \mathrm{m}^{3}\right)$ em comparação com os limites estabelecidos pela

Resolução CONAMA 3/90 nos anos de 2013, 2014, 2015 e 2016.
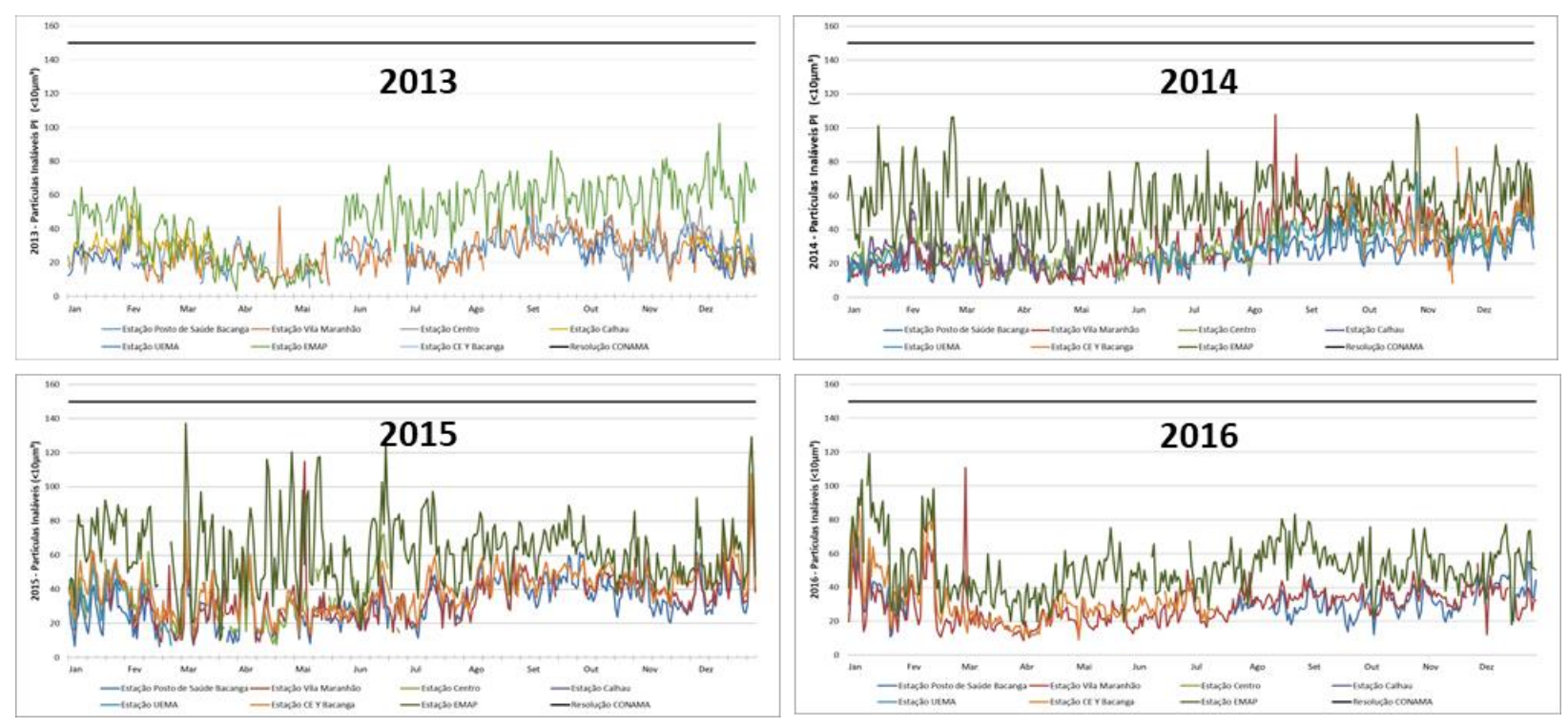

Fonte: VALE/Ecosoft - Org.: Autores, 2019.

Os valores identificados de poluição do ar por PI e PTS para os parâmetros diários em São Luís mantiveram-se, nos anos estudados, em todas as estações, dentro dos índices estabelecidos pela Resolução CONAMA 3/90. Porém, o destaque negativo é a estação EMAP. Após a análise dos quatro anos estudados (2013 a 2016), foi a estação que apresentou os maiores índices de poluição do ar, tanto para poluentes de PTS e PI, dentre todas as estações instaladas em São Luís.

Apesar de não existir um parâmetro estabelecido pela Resolução 3/90 - CONAMA para valores limites de média mensal de poluição por materiais particulados PTS e PI, produzimos a figura 9 com os valores de média mensal de todas as estações a fim de identificar os níveis de variações de poluição no decorrer dos meses e durante a ocorrência sazonal do padrão climático que ocorre na região de uma estação chuvosa (janeiro-junho) e a estação seca ou de estiagem (julho-dezembro).
A forma como a pluviosidade ocorre exerce influência nos níveis de poluição do ar em uma determinada área. Pesquisadores como Guerra e Miranda (2010) chegaram a afirmar que as chuvas fazem com que a atmosfera seja lavada carregando seus poluentes (efeitos washout e rainout). Dessa forma, conforme há um maior volume precipitado, a concentração do poluente diminui de forma efetiva. Afirmam ainda os pesquisadores que a velocidade do vento também influencia de forma direta a concentração dos poluentes porque, quanto maior essa velocidade, maior a dispersão.

A análise da poluição atmosférica por PTS $\left(\mu \mathrm{g} / \mathrm{m}^{3}\right)$ e PI $\left(<10 \mu \mathrm{m}^{3}\right)$ indicou ocorrer variações importantes entre os meses do ano. Destacam-se os meses de março e abril que apresentaram os menores valores de poluição por materiais particulados (PTS - PI), enquanto o mês de setembro indicou ser o mês com os maiores índices de poluição para materiais particulados (PTS - PI). 
Figura 9 - Gráfico da média mensal dos valores registrados nas Estações de Monitoramento do Ar em São Luís (2013 a 2016) para os parâmetros de concentração de Partículas Totais em Suspensão $\left(\mu \mathrm{g} / \mathrm{m}^{3}\right)$ e Partículas Inaláveis $\left(<10 \mu \mathrm{m}^{3}\right)$.

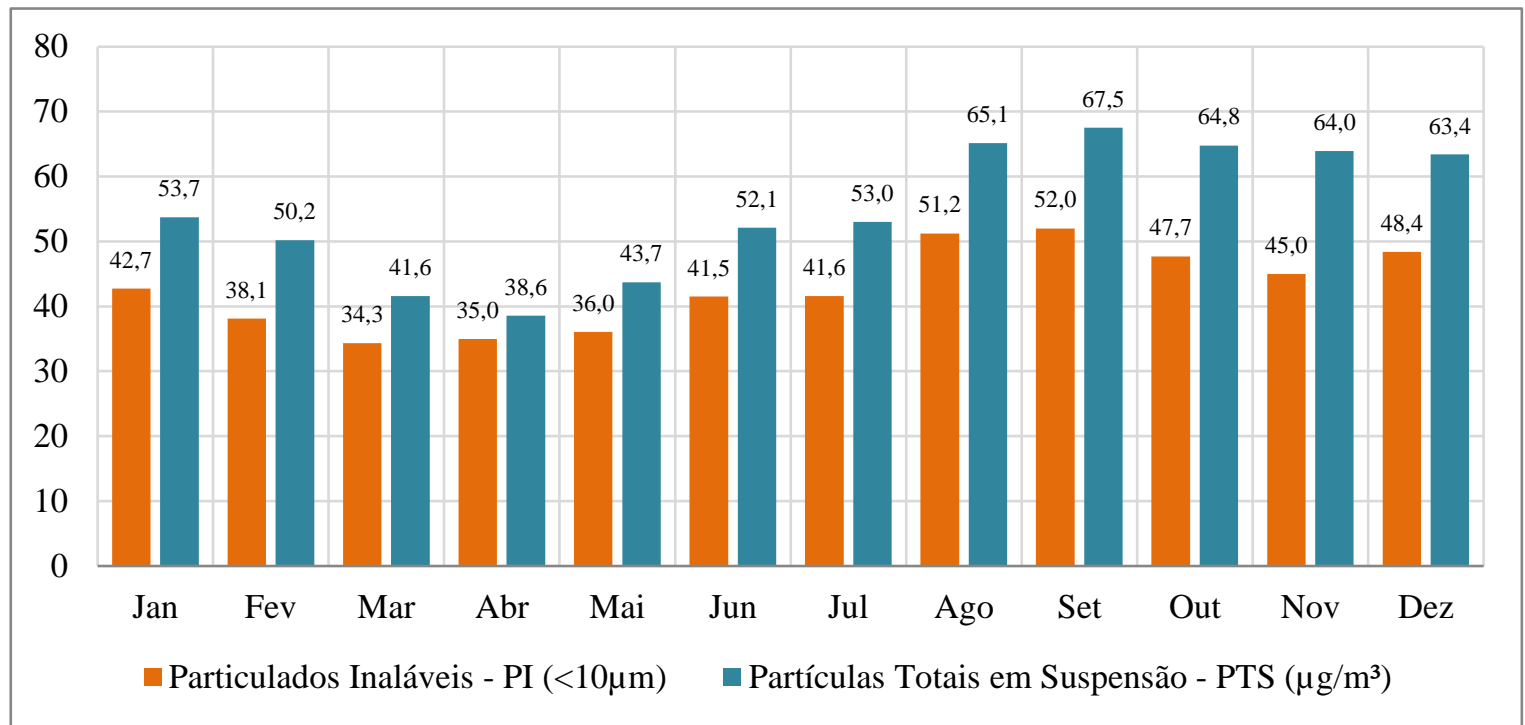

Fonte: VALE/Ecosoft- Org.: Autores, 2019.

Observamos que é nos meses de março e abril que a Normal Climatológica (1981-2010) do INMET para São Luís indica serem os meses com os maiores volumes de chuvas no município, seguidos pelo mês de setembro que apresenta o segundo menor volume de chuvas anuais. É possível, assim, afirmar que em São Luís, entre os meses de julho a dezembro, na estação seca ou de estiagem, ratificando a literatura científica sobre o tema, constata-se aumento dos índices de poluição atmosférica por materiais particulados (PTS - PI) na ordem de 25,6\% para PI e de $35 \%$ para PTS e, nos meses de janeiro a junho, período chuvoso, ocorre uma diminuição dos índices da poluição por materiais particulados (PTS - PI).

\section{CONCLUSÃO}

As análises da poluição atmosférica da área em estudo indicaram que as condições de poluição atmosférica por Partículas Totais em Suspensão (PTS) e Partículas Inaláveis (PI) apresentam-se em condições aceitáveis. A inflexão negativa registrada nos parâmetros de poluição são para os Particulados Inaláveis, que em todos os anos estudados indicou que a RAMQA - Estação EMAP, localizada na Zona Portuária da cidade, excedeu os limites estabelecidos pela Resolução 3/90 - CONAMA. A estação EMAP ultrapassou os limites de poluição de PI em $68 \%$ com valores de $83,8\left(<10 \mu \mathrm{m}^{3}\right)$ no ano de 2013 , em $87 \%$ com valores de $93,4\left(<10 \mu \mathrm{m}^{3}\right)$ no ano de 2014, em $110 \%$ com valores de $105\left(<10 \mu \mathrm{m}^{3}\right)$ no ano de 2015 e em $2 \%$ com valores de $51,1\left(<10 \mu \mathrm{m}^{3}\right)$ no ano de 2016.

Destacamos também que, entre os meses de julho a dezembro, na estação seca ou de estiagem, registrou-se aumento dos índices de poluição atmosférica por materiais particulados (PTS - PI) e nos meses de janeiro a junho, período chuvoso, ocorre uma diminuição dos índices da poluição por materiais particulados PTS e PI.

Ao associarmos as condições características do vento com a poluição atmosférica, foi possível identificar, também, que, tendo o vento características de direção predominante nordeste, a zona urbana do município é favorecida por estar localizada em direção oposta ao vento de onde ocorrem as maiores gerações de poluição atmosférica, identificada na zona portuária e industrial do município.

Deste modo, concluímos que a compreensão da poluição urbana em qualquer cidade não depende apenas das fontes poluidoras e os volumes emitidos na atmosfera, mas também de outros fatores geográficos como a sua dinâmica climática, geomorfológica, padrão de construções, dinâmica portuária e industrial, ou seja, aspectos que podem influenciar na concentração ou dispersão de poluentes. Estes fatores devem, portanto, serem analisados sob uma perspectiva geográfica, ou seja, de forma integrada e dinâmica. 


\section{AGRADECIMENTOS}

O autor Emerson Galvani agradece ao CNPQ pela Bolsa de pesquisador 1D.

\section{REFERÊNCIAS}

BRASIL. CONAMA. Resolução $\mathbf{n}^{\circ} 03$ de 1990. Estabelece os padrões de qualidade do ar, métodos de amostragem e análise dos poluentes atmosféricos. Diário Oficial da República Federativa do Brasil. Poder Executivo. Ministério do Meio Ambiente. Brasília. 22 ago 1990. Seção I. p. 15.937-15.939.

BRAGA, B. et al. Introdução à engenharia ambiental, 2. ed. - São Paulo: Pearson Prentice Hall, p. 305, 2005.

DA SILVA, C. A. Estudos e técnicas de pesquisa de clima urbano como foco no subsistema físicoquimico, novos instrumentos, novas possibilidades. In: Clima e Gestão do Território. Paco Editorial, Jundiaí, p. 51 a 68, 2016. https://doi.org/10.11606/rdg.v0ispe.121848

DAVIS, M. L. CORNWELL, D. A. Introduction to environmental engineering: McGraw-Hill Companies, xvi, p.1008, 2008.

GARREAUD, D. R. RUTLLANT, J. Factores meteorologicos de la contaminación atmosferica en Santiago. In: Episodios criticos de contaminación atmosferica en Santiago. Ed. Coleccion de Química Ambiental, editorial universitária, pp 33-53, 2006.

GOUVEIA et al. Hospitalizações por causas respiratórias e cardiovasculares associadas à contaminação atmosférica no Município de São Paulo, Brasil. Cadernos de Saúde Pública, v. $22, \quad$ n.12, 2669-2677, 2006. https://doi.org/10.1590/S0102-

311X2006001200016

GUERRA, F. P.; MIRANDA, R. M. de. Influência da meteorologia na concentração do poluente atmosférico pm2,5 na RMRJ e na RMSP. Anais do II Congresso Brasileiro de Gestão Ambiental. IBEAS, Londrina - PR, 2011.

INSTITUTO BRASILEIRO DE GEOGRAFIA E ESTATÍSTICA - IBGE. Disponível em: $<$ http://www.ibge.gov.br/home/estatistica/popula cao/censo2010/default.shtm> Acesso em 2016, 2017, 2018 e 2019.

INSTITUTO NACIONAL DE METEOROLOGIA INMET. Disponível em: $<$ http://www.inmet.gov.br/portal/>

LOPES. J. S. L. Participação pública e controle da poluição: a ambientalização dos conflitossociais. Revista de ciências sociais, p.20-30, v.35, n. 1, 2004.

MINISTÉRIO DO MEIO AMBIENTE - MMA.
Plano Nacional de Qualidade do Ar - PNQA. Acessado em 13/02/2019. Disponível em: $<$ http://www.mma.gov.br/cidades-

sustentaveis/qualidade-do-ar/plano-nacional-dequalidade-do-ar>

MILLER, G. T. Ciência ambiental. São Paulo: Thomson Learning, p. 123, 2007.

OKE, T. R. Air pollution in the boundary layer. In: Boundary layer climates. London, Mathuen\& Co, Chap. 9, 1978.

PEITER, P.; TOBAR, C. Poluição do ar e condições de vida: uma análise geográfica de riscos à saúde em Volta Redonda. Rio de Janeiro, Brasil. Caderno de Saúde Pública. Rio de Janeiro. p. 473-485. 1998. https://doi.org/10.1590/S0102311X1998000300003

PINHEIRO, J. M. Clima Urbano da Cidade de São Luís do Maranhão. 2018. 242f. Tese de doutoramento (Programa de Pós-Graduação em Geografia Física) Faculdade de Filosofia, Letras e Ciências Humanas. Universidade de São Paulo, São Paulo, 2018.

PINHEIRO, J.M.; GALVANI, E. Caracterização da direção e velocidade do vento na cidade de São Luís - MA. In: Galvani, E.; GOBO, J.P.A.; LIMA, N. G.B. Climatologia Aplicada II. Curitiba, Ed. CRV, 2018, p. 95-113.

SANTOS, V. A. A qualidade do ar de Dourados (MS): uma contribuição aos estudos de clima urbano com foco no subsistema físico-quimico. In: Clima e Gestão do Território. Paco Editorial, Jundiaí, p. 343 a 371, 2016.

SILVA, Q. D. Mapeamento Geomorfológico da Ilha do Maranhão. Tese (Doutorado em Geografia) - Universidade Estadual Paulista, Presidente Prudente, 2012.

UNITED STATES GEOLOGICAL SURVEY USGS. Disponível em: https://earthexplorer.usgs.gov/ Acesso em mar/2019.

TIAN, L.; HOU, W.; CHEN, J.; CHEN, C.; PAN, X. Spatiotemporal Changes in $\mathrm{PM}_{2.5}$ and Their Relationships with Land-Use and People in Hangzhou. Int. J. Environ. Res. Public Health, 15, 2192, 2018. https://doi.org/10.3390/ijerph15102192

ZHENG, S.; ZHOU, X.; SINGH, R.P.; WU, Y.; YE, Y.; WU, C. The Spatiotemporal Distribution of Air Pollutants and Their Relationship with Land-Use Patterns in Hangzhou City, China. Atmosphere, $\quad 2017$. https://doi.org/10.3390/atmos8060110 